\title{
Hypertonic Saline
}

National Cancer Institute

\section{Source}

National Cancer Institute. Hypertonic Saline. NCI Thesaurus. Code C60814.

Any solution of sodium chloride $(\mathrm{NaCl})$ in water with a concentration of $\mathrm{NaCl}$ higher than that found in physiological saline $(0.9 \% \mathrm{w} / \mathrm{v})$. When administered in vivo, hypertonic saline (HTS) exhibits several physiological effects beneficial to cerebral injury including: 1) osmotic and vasoregulatory - by promoting the flow of excess water from cerebral tissue to the blood via osmosis and decreasing edema in the vascular endothelium of injured tissues, thus lowering vascular resistance and allowing more blood flow; 2) hemodynamic - by effectively expanding plasma volume; 3) immunomodulatory - by preventing leukocytes from becoming activated and adhering to injured neurons and; 4) neurochemical - by counteracting detrimental excitatory amino acids through the normalization of neuronal cell membranes and by restoration of normal electrolyte and neurotransmitter levels in brain cells, and normal cell volumes. 